Mira, M., Gordillo, J., González-Guerrero, O., y Pons, X. (2017): “Análisis comparativo de métodos para la estimación de la emisividad en la banda térmica del sensor TM de Landsat-5”, GeoFocus (Artículos), no 19, p. 55-80. ISSN: 1578$5157 \mathrm{http}: / / \mathrm{dx}$.doi.org/10.21138/GF.512

\title{
ANÁLISIS COMPARATIVO DE MÉTODOS PARA LA ESTIMACIÓN DE LA EMISIVIDAD EN LA BANDA TÉRMICA DEL SENSOR TM DE LANDSAT-5
}

\author{
MARIA MIRA ${ }^{1}$, JAVIER GORDILLO $^{2}$, ÓSCAR GONZÁLEZ-GUERRERO ${ }^{1}$, XAVIER PONS $^{1}$ \\ ${ }^{1}$ GRUMETS Research Group, Departamento de Geografía, Edificio B, Universitat Autònoma de \\ Barcelona, 08193 Bellaterra, España \\ ${ }^{2}$ CREAF, Edificio C, Universitat Autònoma de Barcelona, 08193 Bellaterra, España \\ maria.mira@uab.cat
}

\section{RESUMEN}

El objetivo de este trabajo es comparar las estimaciones de emisividad de la banda térmica del sensor TM de Landsat-5 obtenidas según los algoritmos Valor y Caselles (1996), Sobrino y Raissouni (2000) y Wittich (1997). La evaluación de dichos algoritmos a través de medidas terreno sobre suelos demuestra que proporcionan estimaciones enmarcadas dentro de los valores esperados. Además, se demuestra la capacidad de TM para detectar un aumento significativo (hasta 0.018) de la emisividad de los suelos en función de su contenido de humedad. Asimismo, el estudio pone de manifiesto una discrepancia entre métodos en las estimaciones de emisividad menores a 0.014 , variable según el tipo de cubierta. Un análisis espacio-temporal por clases temáticas permite, de manera similar en los tres métodos, observar los cambios estacionales de los cultivos. En conclusión, la comparación aquí realizada destaca la importancia de la elección del algoritmo a aplicar y de la correcta definición de las constantes de entrada teniendo en cuenta las características espectrales de la zona de estudio.

Palabras clave: emisividad, infrarrojo térmico, Landsat, TM, cubiertas del suelo, NDVI, fracción de cubierta vegetal.

COMPARATIVE ANALYSIS OF EMISSIVITY ESTIMATION METHODS IN THE THERMAL BAND OF THE LANDSAT-5 TM SENSOR

\section{ABSTRACT}

The objective of this work is to compare the emissivity estimates corresponding to the thermal band of the Landsat-5 TM sensor obtained following the algorithms of Valor and Caselles 
Mira, M., Gordillo, J., González-Guerrero, O., y Pons, X. (2017): “Análisis comparativo de métodos para la estimación de la emisividad en la banda térmica del sensor TM de Landsat-5”, GeoFocus (Artículos), no 19, p. 55-80. ISSN: 15785157 http://dx.doi.org/10.21138/GF.512

(1996), Sobrino and Raissouni (2000) and Wittich (1997). Their evaluation through soil field measurements shows that they produce values within the ranges. Furthermore, the capability of TM to detect a significant increase of soils emissivity (up to 0.018) according to their water content is demonstrated. The study shows a discrepancy between the methods in emissivity estimates lower than 0.014, depending on the land cover type. An spatio-temporal analysis by thematic classes allows observing the seasonal changes of crops, reproduced in a similar way by the three methods. To conclude, the presented comparison highlights the importance of choosing both the algorithm to be applied and the correct definition of the input constants taking into account the spectral characteristics of the study area.

Keywords: emissivity, thermal infrared, Landsat, TM, land cover, NDVI, fraction of vegetation cover.

\section{Introducción}

El conocimiento de la temperatura de la superficie terrestre (TST) a partir de datos obtenidos mediante teledetección es clave para el análisis de aspectos como el balance energético o hídrico en la superficie terrestre. Así mismo, la estimación de la TST a partir de imágenes de satélite comprende varias etapas de pre-procesado que incluyen la corrección de los efectos atmosféricos y la estimación de la emisividad térmica de la superficie. La emisividad se define como la relación entre la emisión de la superficie y la emisión de un cuerpo negro a la misma temperatura termodinámica (o cinética) (Norman y Becker, 1995). La emisividad depende fundamentalmente de la composición, la rugosidad y el contenido en humedad de la superficie, y además varía con la longitud de onda y las condiciones de observación (Buettner and Kern, 1965). La exactitud en las estimaciones de emisividad afecta directamente a la exactitud en la estimación de la TST. Mira et al. (2007) observaron que una variación de emisividad de \pm 0.06 provoca un error de $\pm 2.2 \mathrm{~K}$ en la determinación de la TST (a $11 \mu \mathrm{m}$ y para una temperatura de $300 \mathrm{~K}$ ).

La exactitud deseada en la estimación de la TST varía de una aplicación a otra, de acuerdo con las sensibilidades de los procesos implicados en los modelos. Sin embargo, en general, el objetivo es conseguir una exactitud mejor que $1 \mathrm{~K}$ (Seguin et al., 1999). A partir de observaciones instantáneas monocanal en el infrarrojo térmico (IRT) se han observado buenos resultados con el sensor Thematic Mapper (TM) de los satélites Landsat 4 y 5, y con los sensores aeroportados DAIS (e.g., $1 \mathrm{~K}$ sobre zonas agrícolas semiáridas, Sobrino et al., 2004a, 2004b). A partir de observaciones instantáneas de sensores con dos canales o dos ángulos de observación en el IRT, varios experimentos de validación han demostrado proporcionar exactitudes mejores que $1 \mathrm{~K}$. Sin embargo, una exactitud de $1 \mathrm{~K}$ por lo general requiere información local sobre las condiciones de la superficie para corregir los efectos de emisividad. Además, la falta de tal información puede inducir a errores de hasta 3 K (Sobrino et al., 2003, 2004a, 2004c; Sòria y Sobrino, 2006; Coll et al., 2005). A partir de observaciones instantáneas multiespectrales en el IRT, el algoritmo de separación de la temperatura y la emisividad (TES, Gillespie et al., 1998) proporciona estimaciones de la TST con una exactitud de aproximadamente $1 \mathrm{~K}$ (Coll et al., 2003), mientras que el uso de datos 
Mira, M., Gordillo, J., González-Guerrero, O., y Pons, X. (2017): “Análisis comparativo de métodos para la estimación de la emisividad en la banda térmica del sensor TM de Landsat-5”, GeoFocus (Artículos), no 19, p. 55-80. ISSN: 15785157 http://dx.doi.org/10.21138/GF.512

hiperespectrales aumenta la exactitud de la TST hasta 0.5 K (Payan y Royer, 2004). Utilizando observaciones consecutivas de datos multiespectrales en el infrarrojo medio y el IRT las exactitudes obtenidas varían de 0.5 a $2.5 \mathrm{~K}$, según lo demostrado por diferentes estudios de sensibilidad (Dash et al., 2002, 2005; Peres y DaCamara, 2004), por experimentos de validación con adquisiciones del par día y noche (Wan et al., 2002, 2004), y por intercomparaciones de las adquisiciones obtenidas con el método TES aplicadas a datos del sensor satelitario Advanced Spaceborne Thermal Emission and Reflection Radiometer (ASTER) (Jacob et al., 2004).

La estimación de la emisividad de la superficie a partir de datos de teledetección no es sencilla. Si disponemos de un sensor multiespectral en el IRT podríamos cartografiar la emisividad espectral de la superficie utilizando, por ejemplo, el algoritmo TES propuesto por Gillespie et al. (1998), originariamente aplicado a datos del sensor ASTER. Sin embargo, en sensores como el TM o el Enhanced Thematic Mapper plus (ETM+) de Landsat no es posible obtener la emisividad directamente ya que tienen una única banda en el IRT. Se trata del conocido problema de separación de la temperatura y la emisividad (Gillespie et al., 1998), puesto que tenemos más incógnitas que ecuaciones. Para solucionar el problema una posibilidad es considerar relaciones empíricas adicionales entre las variables incógnitas. Concretamente, un método alternativo consiste en utilizar relaciones con los índices de vegetación o las medidas de reflectancia en el espectro solar (Van de Griend y Owe, 1993; Olioso, 1995; Valor y Caselles, 1996; Wittich, 1997; Sobrino y Raissouni, 2000; Olioso et al., 2007; Caselles et al., 2012). Así, tenemos que a partir de índices de vegetación o medidas de reflectancias es posible estimar la emisividad espectral de superficies naturales con errores que habitualmente se sitúan alrededor del $1 \%$ al $2 \%$. El enfoque más clásico que relaciona la emisividad con el índice de vegetación de diferencia normalizada (NDVI) fue establecido por primera vez experimentalmente por Van de Griend y Owe (1993). Años más tarde, diversos autores publicaron otras aproximaciones en la misma línea.

Difícilmente se poseen medidas in situ de emisividad simultáneas al paso del satélite y sobre cada una de las cubiertas existentes en la imagen. Además, la medida de la emisividad de una cubierta vegetal es compleja debido a la propia estructura de la cubierta. La validación de las estimaciones de emisividad obtenidas con datos de sensores a bordo de satélite con medidas terreno es, por lo tanto, complicada. No obstante, las estimaciones de emisividad procedentes de otras campañas experimentales y las medidas de laboratorio pueden servir como referencia para evaluar las estimaciones de satélite, lejos de considerarlo como una validación. La estimación de la emisividad en el campo o en el laboratorio es posible mediante el uso de radiómetros en el IRT y según diversos procedimientos (Wan y Dozier, 1989; Nerry et al., 1990a, 1990b; Salisbury y d'Aria, 1992a, 1992b; Rubio et al., 2007). El procedimiento de referencia es el "método de la caja", originalmente propuesto por Buettner y Kern (1965) y Dana (1969), y mejorado con la versión de dos tapas por Rubio et al. (1997, 2003). De acuerdo con Mira et al. (2007), el método de la caja en su versión de dos tapas permite la determinación de la emisividad espectral con un error experimental medio de \pm 0.005 . Este error será el considerado en el presente estudio como el error aceptable para la estimación de la emisividad y se tendrá en cuenta a la hora de analizar las diferencias entre métodos.

El principal objetivo de este trabajo es analizar las estimaciones de emisividad de tres diferentes algoritmos aplicados a datos del sensor monocanal Thematic Mapper (TM) del satélite Landsat-5. Se evaluarán cualitativa y cuantitativamente los cambios producidos entre las 
Mira, M., Gordillo, J., González-Guerrero, O., y Pons, X. (2017): “Análisis comparativo de métodos para la estimación de la emisividad en la banda térmica del sensor TM de Landsat-5”, GeoFocus (Artículos), no 19, p. 55-80. ISSN: 15785157 http://dx.doi.org/10.21138/GF.512

estimaciones de emisividad obtenidas según dichos algoritmos. Además, se analizarán los posibles patrones temporales y espaciales de la emisividad sobre las principales cubiertas del suelo presentes en la zona de estudio. Para llevar a cabo el objetivo de la investigación se consideró una serie temporal de imágenes Landsat-5 tomadas sobre una zona heterogénea en cubiertas del suelo: el Delta del Ebro y sus alrededores, en la costa mediterránea de la Península Ibérica.

El presente documento se ha estructurado de la manera siguiente. Tras la previa introducción (Sección 1), se dan los detalles sobre los datos utilizados (Sección 2) y la metodología aplicada (Sección 3). A continuación, se presenta la descripción y el análisis de los resultados (Sección 4). Finalmente, se expone la discusión (Sección 5) y la principal conclusión obtenida (Sección 6).

\section{Materiales}

\subsection{Delimitación espacial y temporal}

La región de estudio se encuentra localizada en la parte nororiental de la Península Ibérica, más concretamente en la provincia de Tarragona, al sureste de Cataluña. Se trata del Delta del Ebro y sus alrededores, abarcando territorios del este de Aragón y el norte de la Comunidad Valenciana. Se trata de una zona relativamente llana, interesante para la teledetección debido a su gran heterogeneidad en cubiertas del suelo, producto del gran contraste de esta área húmeda, con una gran diversidad de cultivos y prácticas agrícolas.

El periodo temporal y los días concretos analizados en este estudio estuvieron determinados por las fechas de adquisición de las imágenes Landsat-5 seleccionadas, adquiridas alrededor de las 10:15 UTC. Concretamente, se consideraron ocho imágenes adquiridas en las diferentes épocas del año, durante los años 2009 (marzo, mayo y septiembre), 2010 (marzo y agosto) y 2011 (marzo, abril y mayo). Esto nos permitió analizar la posible variabilidad temporal de la emisividad a causa de diferencias en la cubierta vegetal (i.e., evolución de los cultivos, períodos de sequía, etc.).

\subsection{Imágenes Landsat-5}

Landsat-5 fue un satélite artificial de la National Aeronautics and Space Administration (NASA) y del United States Geological Survey (USGS) destinado a la observación de los recursos naturales de la Tierra. Lanzado en 1984 y operativo hasta 2012, seguía una órbita heliosíncrona y polar a una altitud nominal de $705 \mathrm{~km}$. Su resolución temporal era de 16 días y llevaba a bordo dos instrumentos principales: el sensor Multispectral Scanner System (MSS), embarcado principalmente para dar continuidad a los datos obtenidos por este sensor desde las primeras misiones Landsat, y el sensor Thematic Mapper (TM). En este estudio se consideraron imágenes tomadas por el sensor TM, caracterizado por sus 7 bandas espectrales, que incluyen 5 bandas del visible al infrarrojo de onda corta (bandas 1 a 5 y 7, con una resolución espacial de $30 \mathrm{~m}$ ) y una banda en el infrarrojo térmico (banda 6: 10.4-12.5 $\mu \mathrm{m}$, con una resolución espacial de $120 \mathrm{~m}$ ). Las escenas se captaban con un ancho de barrido aproximado de $180 \mathrm{~km}$ y se distribuyen en imágenes aproximadamente cuadradas. 
Mira, M., Gordillo, J., González-Guerrero, O., y Pons, X. (2017): “Análisis comparativo de métodos para la estimación de la emisividad en la banda térmica del sensor TM de Landsat-5”, GeoFocus (Artículos), no 19, p. 55-80. ISSN: 1578$5157 \mathrm{http}: / / \mathrm{dx}$.doi.org/10.21138/GF.512

Destacar que el ámbito y extensión de las imágenes varía según el organismo que proporciona los datos (i.e., ESA o USGS) y según su fecha de adquisición. Por tanto, fue necesaria su adaptación a unas coordenadas comunes mediante el correspondiente recorte a la zona de interés.

Las imágenes proporcionadas por el USGS estaban ya corregidas geométricamente, mientras que las de la ESA fueron corregidas siguiendo la metodología descrita por Pons et al. (2010) basada en Palà y Pons (1995). La corrección radiométrica de todas las imágenes fue realizada siguiendo el método de corrección automática propuesto por Pons et al. (2014). Éste considera como referencia las reflectancias obtenidas en áreas pseudoinvariantes localizadas a partir de productos del sensor Moderate Resolution Imaging Spectroradiometer (MODIS) del satélite Terra. El algoritmo permite el tratamiento de una gran cantidad de imágenes en relativamente poco tiempo, obteniendo valores radiométricos altamente consistentes en toda la serie de imágenes. De forma excepcional, debido a la baja disponibilidad de zonas pseudoinvariantes para ajustar el modelo a causa de la presencia de nubes, un par de imágenes (marzo 2010 y 2011) fueron corregidas radiométricamente de forma manual según el método descrito por Pons y Solé-Sugrañes (1994). Este método utiliza los valores radiométricos mínimos observados en cada una de las bandas, sin incluir la banda térmica, correspondientes a píxeles en zonas de sombra completa (autosombra o sombra proyectada).

Las correspondientes máscaras de agua y nubes se generaron para evitar posibles valores sin sentido físico en los productos obtenidos a posteriori (i.e., fracción de cubierta vegetal, índices de vegetación, emisividad). La metodología se basó en un proceso de fotointerpretación y digitalización que permitió obtener un polígono de toda la línea de costa y la localización de los píxeles clasificados como nubes y sus sombras.

\subsection{Mapa de cubiertas}

Si bien disponemos de otros mapas de cubiertas, como GlobCover (WWW1) y SIOSE (WWW2), se consideró la cartografía CORINE (WWW3; Bossard et al., 2000) como la óptima, debido no sólo a la afinidad entre su leyenda y la utilizada en el estudio de Caselles et al. (2012), sino también a la afinidad entre su resolución espacial $(100 \mathrm{~m})$ y las de las imágenes Landsat (30 m). El mapa de cubiertas CORINE es un producto responsabilidad de la Agencia Europea del Medio Ambiente, actualmente incluido en el Land Core Monitoring System del proyecto Copernicus [originalmente denominado GMES (Global Monitoring for Environment and Security)], iniciativa de la Comisión Europea. Realizado a una escala 1:100 000, se basa en la fotointerpretación sobre imágenes de referencia Landsat-5 TM del año 1990, de Landsat-7 del año 2000 y SPOT-4 del año 2006. En la distribución de que se ha dispuesto se trata de una rasterización a $100 \mathrm{~m}$ de costado de celda.

El mapa de cubiertas fue adaptado al ámbito de estudio y a la resolución espacial de las imágenes de satélite. Esto último se realizó aplicando un remuestreo espacial siguiendo el método del vecino más próximo (nearest neighbor). Posteriormente se reclasificaron las 33 categorías presentes en la zona de estudio siguiendo la metodología propuesta por Coll et al. (2012), agrupándolas en 9 categorías más generales. En la figura 1 se muestra el mapa de cubiertas resultante, y en la tabla 1 se detallan las leyendas inicial y final consideradas. 


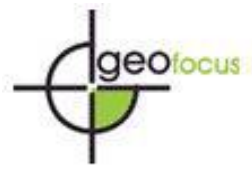

Mira, M., Gordillo, J., González-Guerrero, O., y Pons, X. (2017): “Análisis comparativo de métodos para la estimación de la emisividad en la banda térmica del sensor TM de Landsat-5”, GeoFocus (Artículos), nº 19, p. 55-80. ISSN: 15785157 http://dx.doi.org/10.21138/GF.512

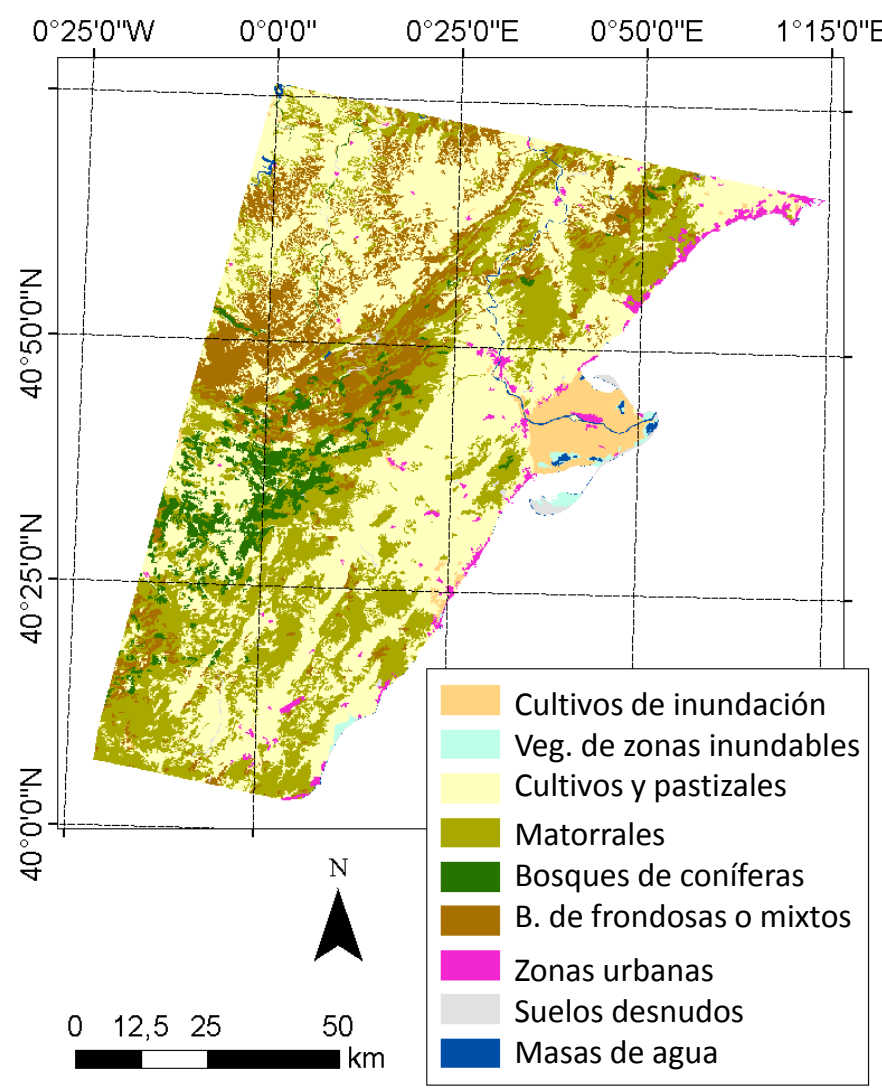

Sistema de coordenadas: WGS 1984 UTM Huso $31 \mathrm{~N}$

Proyección: Universal Transversal de Mercator

Datum: WGS 1984

Unidades: Metros

Figura 1. Mapa correspondiente al ámbito de estudio: región del Delta del Ebro y sus alrededores, en el noreste de la Península Ibérica. Clasificación de las cubiertas del suelo de la zona de estudio, considerando el mapa CORINE 2006 reclasificado siguiendo las indicaciones de la tabla 1.

\subsection{Modelo digital de elevaciones}

Para la corrección radiométrica y geométrica de las imágenes se consideró un modelo digital de elevaciones con una resolución espacial de $30 \mathrm{~m}$, generado a partir de hojas 1:5000 del Instituto Geográfico Nacional (IGN) a 5 m de resolución espacial.

\subsection{Base de datos de emisividad}

Se consideró una extensa base de datos de medidas de emisividad entre los 10 y $12 \mu \mathrm{m}$ tomadas in situ según el método de la caja (Rubio et al., 1997) con radiómetros térmicos. Los datos, procedentes de diversos estudios, están resumidos en las tablas 2 y 3 de Mira et al. (2015). Se trata 
Mira, M., Gordillo, J., González-Guerrero, O., y Pons, X. (2017): “Análisis comparativo de métodos para la estimación de la emisividad en la banda térmica del sensor TM de Landsat-5”, GeoFocus (Artículos), no 19, p. 55-80. ISSN: 1578$5157 \mathrm{http}: / / \mathrm{dx}$.doi.org/10.21138/GF.512

de medidas realizadas sobre un territorio de características similares a las de la zona de estudio de este proyecto: La Crau y la zona experimental Alpilles-ReSeDA, una pequeña área agrícola a medio camino entre la región Crau-Camargue y Avignon, al sureste de Francia. La base de datos incluye también medidas tomadas sobre cultivos bien desarrollados en otras áreas Mediterráneas (la Albufera de Valencia, Barrax, Marrakech). Los valores medios de emisividad observados sobre suelos desnudos secos varían de 0.963 a 0.973 , y los húmedos de 0.975 a 0.986 .

Tabla 1. Equivalencia entre las categorías iniciales del CORINE 2006 y las categorías asignadas tras su reclasificación.

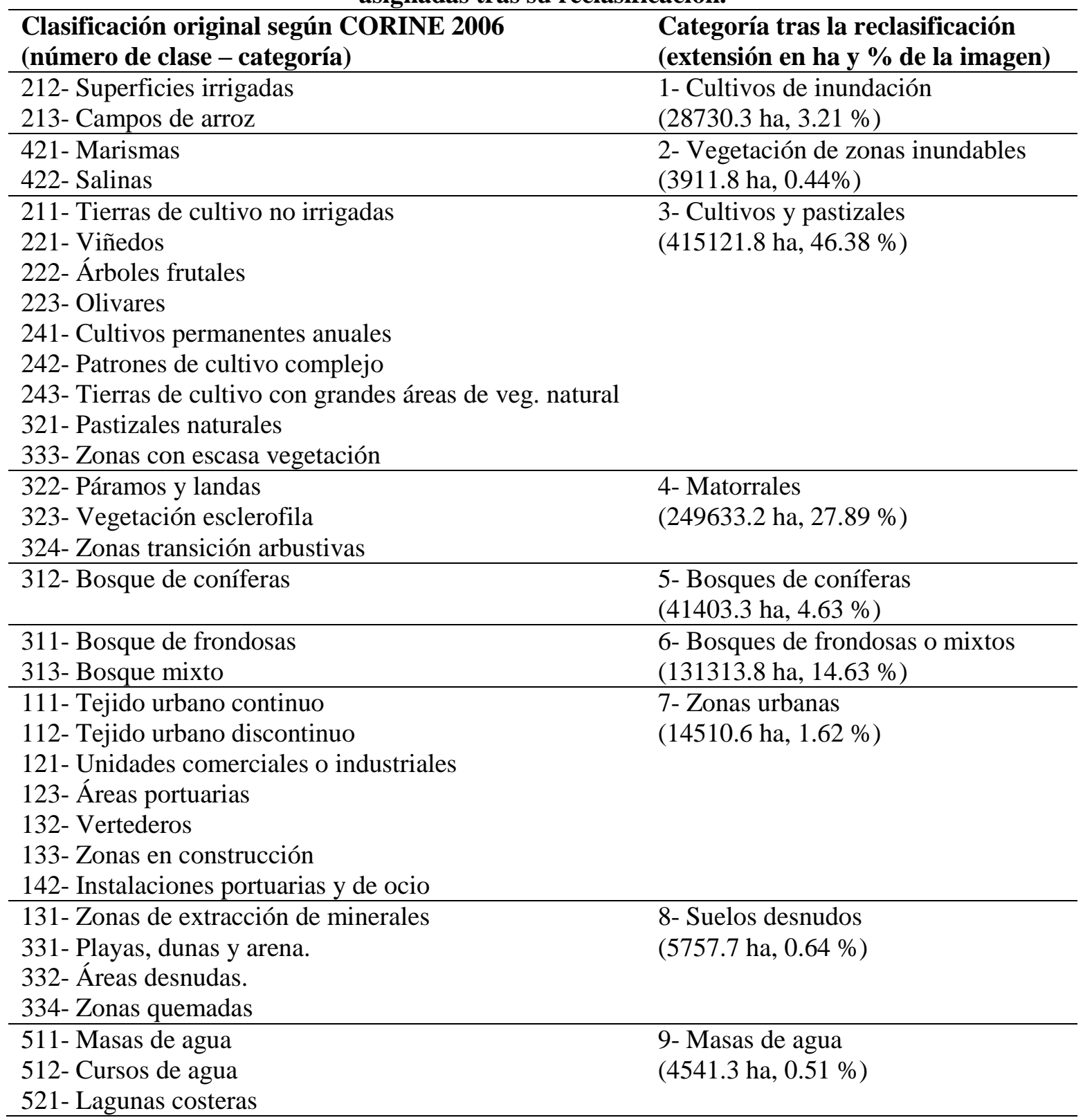




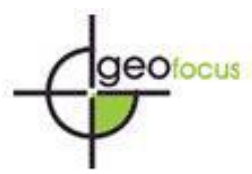

Mira, M., Gordillo, J., González-Guerrero, O., y Pons, X. (2017): “Análisis comparativo de métodos para la estimación de la emisividad en la banda térmica del sensor TM de Landsat-5”, GeoFocus (Artículos), nº 19, p. 55-80. ISSN: 1578$5157 \mathrm{http}: / / \mathrm{dx}$.doi.org/10.21138/GF.512

Además, se consideró la base de datos de espectros continuos de emisividad medidos en el laboratorio correspondientes a la librería espectral Advanced Spaceborne Thermal Emission Reflection Radiometer (ASTER) (Baldridge et al., 2009) (WWW4). El número de muestras disponibles en la librería, correspondientes a cada clase de cubierta según la clasificación propuesta por Coll et al. (2012) se detalla en la tabla 2.

Tabla 2. Número de muestras disponibles (N) en la librería espectral ASTER correspondientes a cada cubierta según la clasificación propuesta por Coll et al. (2012).

\begin{tabular}{llc}
\hline $\begin{array}{l}\text { Cubierta } \\
\text { (Coll } \text { et al., 2012) }\end{array}$ & $\begin{array}{l}\text { Muestras de la } \\
\text { librería espectral ASTER }\end{array}$ & $\mathbf{N}$ \\
\hline $\begin{array}{l}\text { 1. Vegetación inundada, cultivos y prados } \\
\text { 3. Cultivos y prados }\end{array}$ & (Vegetación) hierba verde & 1 \\
\hline $\begin{array}{l}\text { 2. Bosques inundados y matorrales } \\
\text { 4. Matorrales }\end{array}$ & (Vegetación) coníferas y caducifolios & 2 \\
\hline 5. Bosques de hoja caduca & (Vegetación) caducifolio & 1 \\
\hline 6. Bosques de hoja perenne & (Vegetación) conífera & 1 \\
\hline 7. Zonas urbanas & (Urbano-tejados) baldosas y caucho & 4 \\
\hline & (Urbano-paredes) hormigón & 4 \\
\hline & (Urbano-pavimento) asfalto & 3 \\
\hline 8. Roca desnuda & Roca desnuda & 388 \\
\hline 9. Agua & Agua & 2 \\
\hline & Suelo & 52 \\
\hline
\end{tabular}

\section{Metodología}

Para alcanzar los objetivos marcados se procedió de la siguiente manera. En primer lugar, se cartografió la emisividad según los tres algoritmos considerados. A continuación, se evaluaron las estimaciones de satélite con la base de datos de medidas terreno. Después se analizó la evolución temporal por clases temáticas. Por último, se realizó una comparación de métodos relativa a uno de ellos tomado como referencia.

Los métodos de emisividad considerados son el método de la cubierta vegetal propuesto por Valor y Caselles (1996), el método de los umbrales del NDVI propuesto por Sobrino y Raissouni (2000), y el método propuesto por Wittich (1997). Los dos primeros consideran una superficie mezcla de suelo desnudo y vegetación, dependen del índice de fracción de cubierta vegetal y tienen en cuenta el efecto de cavidad de los objetos de la superficie. Ambos también requieren de la estimación de diversos parámetros efectivos, variables según la cubierta del suelo, por lo que se precisa un mapa de cubiertas del suelo. Además son válidos solamente en medios isotérmicos, es decir, cuando la temperatura del suelo y la vegetación se asemejan entre sí, condición que difícilmente se cumple a mediodía en un área seca y caliente. El método de Wittich (1997), en cambio, requiere solamente un conocimiento previo de los valores extremos del índice de vegetación NDVI. A continuación explicamos con detalle cada uno de los métodos. 
Mira, M., Gordillo, J., González-Guerrero, O., y Pons, X. (2017): “Análisis comparativo de métodos para la estimación de la emisividad en la banda térmica del sensor TM de Landsat-5”, GeoFocus (Artículos), no 19, p. 55-80. ISSN: 1578$5157 \mathrm{http}: / / \mathrm{dx}$. doi.org/10.21138/GF.512

\subsection{Método de la cubierta vegetal}

Este método, propuesto por Valor y Caselles (1996) (en adelante identificado como "Valor1996"), permite el cálculo de la emisividad en la banda térmica del sensor TM de Landsat. Considera una expresión dependiente del índice de la fracción de cubierta vegetal $(f)$ y de los valores mínimo $\left(\varepsilon_{s}\right)$ y máximo $\left(\varepsilon_{v}\right)$ de la emisividad en dicha banda espectral y para cada tipo de cubierta. Dichos valores corresponden a una superficie de suelo desnudo y a una superficie totalmente cubierta del correspondiente tipo de vegetación, respectivamente. Además, depende de otro parámetro llamado índice de cavidad $(<d \varepsilon>)$. La expresión es la siguiente:

$$
\varepsilon=\varepsilon_{v} f+\varepsilon_{s}(1-f)+4\langle d \varepsilon\rangle f(1+f)
$$

siendo $f$ el índice de la fracción de cubierta vegetal, definido como (Valor y Caselles, 1996):

$$
f=\frac{1-\frac{N D V I}{N D V I_{S}}}{\left(1-\frac{N D V I}{N D V I_{S}}\right)-K\left(1-\frac{N D V I}{N D V I_{V}}\right)}
$$

donde los subíndices $s$ y $v$ hacen referencia a una cubierta de suelo desnudo y una cubierta de vegetación completa, respectivamente. NDVI corresponde al índice de vegetación de diferencia normalizada, definido en función de la reflectancia en la banda del infrarrojo cercano $\left(\rho_{\text {irc }}\right)$ y la del rojo $\left(\rho_{r}\right)$ (Rouse et al., 1974):

$$
N D V I=\frac{\rho_{i r c}-\rho_{r}}{\rho_{i r c}+\rho_{r}}
$$

y K corresponde a un factor definido como:

$$
K=\frac{\rho_{i r c v}-\rho_{r v}}{\rho_{\text {irc } s}-\rho_{r s}}
$$

Para el cálculo del índice de fracción de cubierta vegetal $f$, tras enmascarar los píxeles clasificados como zonas urbanas, masas de agua o suelos desnudos, se calcularon los percentiles del $5 \%$ y $95 \%$ de cada una de las imágenes. Dichos valores se consideraron como los valores extremos de NDVI, asignados a una cubierta de suelo desnudo $\left(N D V I_{s}\right)$ y a una cubierta de vegetación completa $\left(N D V I_{v}\right)$. El factor K se calculó tras considerar el valor medio de las reflectancias $\rho_{\text {irc }} \mathrm{y} \rho_{r}$ de los píxeles con $\mathrm{NDVI}>\mathrm{NDVI}_{\mathrm{v}}$ y $\mathrm{NDVI}<\mathrm{NDVI}_{\mathrm{s}}$. Los píxeles con valores $\mathrm{NDVI}>\mathrm{NDVI}_{\mathrm{v}} \mathrm{o}$ NDVI $<\mathrm{NDVI}_{\mathrm{s}}$ (un volumen de datos inferior al $10 \%$ de la imagen), por la propia definición de la ecuación 2, proporcionan valores de $f$ físicamente poco o nada significativos (i.e., $f<0$ o $f>1$ ), por lo que se les asignó el valor extremo $(f=0$ o $f=1$, respectivamente).

Los valores de los coeficientes $\varepsilon_{s}, \varepsilon_{v} \mathrm{y}<d \varepsilon>$ de la ecuación 1 fueron derivados para cada una de las clases establecidas por Coll et al. (2012) (ver tabla 2), utilizando la base de datos de espectros de emisividad de la librería espectral ASTER y considerando el valor medio. Los espectros fueron convolucionados según la banda espectral térmica de Landsat-5, siguiendo la ecuación: 
Mira, M., Gordillo, J., González-Guerrero, O., y Pons, X. (2017): “Análisis comparativo de métodos para la estimación de la emisividad en la banda térmica del sensor TM de Landsat-5”, GeoFocus (Artículos), n 19, p. 55-80. ISSN: 15785157 http://dx.doi.org/10.21138/GF.512

$$
\varepsilon_{\lambda_{1}-\lambda_{2}}=\frac{\int_{\lambda_{1}}^{\lambda_{2}} s_{\lambda}^{\prime}\left(1-\rho_{\lambda}\right) B_{\lambda}(T) d \lambda}{\int_{\lambda_{1}}^{\lambda_{2}} S_{\lambda}^{\prime} B_{\lambda}(T) d \lambda}
$$

donde $\lambda_{1}-\lambda_{2}$ corresponde al intervalo espectral 10.4-12.5 $\mu \mathrm{m}$ de la banda 6 de Landsat-5, $S$ ' es la sensibilidad espectral normalizada, $\left(1-\rho_{\lambda}\right)$ es la emisividad espectral de acuerdo con la ley de Kirchhoff, y $B_{\lambda}(T)$ es la reflectancia espectral de un cuerpo negro a una temperatura de $300 \mathrm{~K}$.

El término de cavidad $\langle d \varepsilon>$ tiene en cuenta los efectos de las reflexiones internas de las superficies y para observaciones cercanas al nadir viene definido como (Caselles y Sobrino, 1989):

$$
d \varepsilon=\left(1-\varepsilon_{s}\right) \varepsilon_{v} F(1-f)
$$

siendo $\mathrm{F}$ un factor forma que depende de la altura $(\mathrm{H})$ y la separación $(\mathrm{S})$ entre los elementos de la superficie, y considera la transmisión de energía entre ellos:

$$
F=\left(1+\frac{H}{S}\right)-\sqrt{1+\left(\frac{H}{S}\right)^{2}}
$$

En la tabla 3 se recogen los valores considerados para los factores H y S (Caselles et al., 2012), teniendo en cuenta la descripción de la vegetación de cada clase.

Tabla 3. Valores utilizados para el cálculo del factor de forma (F) y su desviación estándar, siendo H y S la altura y separación entre los elementos de la superficie, respectivamente.

\begin{tabular}{lll}
\hline Clase & H $(\mathbf{m})$ & $\mathbf{S ~}(\mathbf{m})$ \\
\hline 2. Vegetación de zonas inundables & $3 \pm 1$ & $3 \pm 1$ \\
\hline 4. Matorrales & $3 \pm 1$ & $3 \pm 1$ \\
\hline 5. Bosques de coníferas & $15 \pm 5$ & $5 \pm 2$ \\
\hline 6. Bosques de frondosas o mixtos & $15 \pm 5$ & $5 \pm 2$ \\
\hline
\end{tabular}

\subsection{Método de los umbrales del NDVI}

El segundo método es el propuesto por Sobrino y Raissouni (2000) e identificado a partir de ahora como "Sobrino2000". Para el cálculo de la emisividad en la banda térmica de Landsat, al igual que el método anterior, considera el índice de la fracción de cubierta vegetal $(f)$ y el factor de cavidad $(\langle d \varepsilon>)$. Sin embargo, considera valores de NDVI umbrales para distinguir entre píxeles categorizados como suelo desnudo (ecuación 8), mixtos (ecuación 9) o vegetación completa (ecuación 10):

$$
\begin{aligned}
& \text { Si NDVI }<D V I_{s}: \quad \varepsilon_{s}=0.98-0.042 \rho_{r} \\
& \text { Si NDVI } I_{S} \leq N D V I \leq N D V I_{v}: \quad \varepsilon=\varepsilon_{v} f+\varepsilon_{s}(1-f)+<d \varepsilon> \\
& \text { Si NDVI }>N D V I_{v}: \quad \varepsilon_{v}=0.985+<d \varepsilon>
\end{aligned}
$$


Mira, M., Gordillo, J., González-Guerrero, O., y Pons, X. (2017): “Análisis comparativo de métodos para la estimación de la emisividad en la banda térmica del sensor TM de Landsat-5”, GeoFocus (Artículos), n 19, p. 55-80. ISSN: 15785157 http://dx.doi.org/10.21138/GF.512

\subsection{Algoritmo de Wittich1997}

El tercer método de emisividad analizado fue el propuesto por Wittich (1997), a partir de ahora identificado como "Wittich1997". Este algoritmo relaciona la emisividad con el índice de vegetación NDVI siguiendo la expresión:

$$
\varepsilon=\varepsilon_{v}-\left(\varepsilon_{v}-\varepsilon_{g}\right)\left(\frac{N D V I_{v}-N D V I}{N D V I_{v}-N D V I_{s}}\right)^{k}
$$

donde $k$ es un coeficiente que depende principalmente del ángulo medio de inclinación de las hojas y del ángulo de observación. Diversos estudios de simulación (Anton y Ross, 1990; Olioso, 1995; François et al., 1997) demostraron que el coeficiente $k$ puede tomar valores entre 1 y 3.

\subsection{Métricas para el análisis de errores}

Para analizar la exactitud de las estimaciones de emisividad, se consideraron diversas métricas estándares: el error cuadrático medio absoluto $\left(R M S E_{a}\right)$ y relativo $\left(R M S E_{r}\right)$, y el sesgo (Bias). Los estadísticos se definen como:

$$
\begin{array}{r}
R M S E_{a}=\sqrt{\frac{\sum_{i=1}^{N}\left(y_{i}-x_{i}\right)^{2}}{N}} \\
R M S E_{r}(\%)=\frac{R M S E_{a}}{\operatorname{mean}\left(x_{i}\right)} 100 \\
\text { Bias }=\frac{\sum_{i=1}^{N}\left(y_{i}-x_{i}\right)}{N}
\end{array}
$$

donde $y$ es el valor estimado por la imagen problema, $x$ es el valor en la imagen de referencia y $N$ el número de píxeles, identificados con el subíndice $i$.

Debido al gran tamaño de las imágenes y con el objetivo de tener una estimación general de las métricas independientemente del tipo de suelo, se optó por una selección arbitraria de píxeles que incluyeran los mínimos y máximos de cada cubierta y que se encontraran distribuidos a lo largo de todo el área de estudio. Además, limitamos el estudio a dos imágenes tomadas en diferentes épocas del año: setiembre de 2009 y mayo del 2011.

\section{Descripción y análisis de resultados}

\subsection{Coeficientes para el cálculo de la emisividad}

En la tabla 4 y tabla 5 se detallan los valores de los coeficientes utilizados en el algoritmo Valor1996 para el cálculo de la emisividad, obtenidos siguiendo la metodología explicada en la 
Mira, M., Gordillo, J., González-Guerrero, O., y Pons, X. (2017): “Análisis comparativo de métodos para la estimación de la emisividad en la banda térmica del sensor TM de Landsat-5”, GeoFocus (Artículos), nº 19, p. 55-80. ISSN: 15785157 http://dx.doi.org/10.21138/GF.512

sección precedente. Sobrino y Raissouni (2000) propusieron valores de $\mathrm{NDVI}_{\mathrm{s}}=0.2$ y $\mathrm{NDVI}_{\mathrm{v}}=0.5$, semejantes a los calculados en este estudio para cada día (ver tabla 5). Sin embargo, para ganar en exactitud y por coherencia con el método Valor1996, se consideraron los valores de la tabla 5. En cambio, para la aplicación del método Wittich1997 se utilizaron los valores de $\mathrm{NDVI}_{\mathrm{s}}=0.08$ y $\mathrm{NDVI}_{\mathrm{v}}=0.90$, en concordancia con los valores considerados por Mira et al. (2015). El valor de $\mathrm{NDVI}_{\mathrm{s}}$ fue establecido por Mira et al. (2015) tras considerar una larga serie de datos de reflectancias de suelos medidos en el laboratorio, y el de $\mathrm{NDVI}_{\mathrm{v}}$ en relación a los valores observados en las imágenes.

Tabla 4. Valor medio y desviación estándar de los coeficientes de emisividad para diferentes clases de cubiertas del suelo, necesarios para estimar la emisividad de la banda térmica de Landsat-5 según los métodos Valor1996 y Sobrino2000 . $\varepsilon_{s}:$ emisividad de un suelo desnudo; $\varepsilon_{v}$ : emisividad de una cubierta de vegetación completa; $\langle d \varepsilon\rangle$ : factor de cavidad; $d$ : indica suelos secos; $w$ : indica suelos húmedos.

\begin{tabular}{llll}
\hline \multicolumn{4}{l}{ Banda 6 de Landsat-5 TM (10.4-12.5 $\boldsymbol{\mu m})$} \\
\hline Clase & $\boldsymbol{\varepsilon}_{\boldsymbol{v}}$ & $\boldsymbol{\varepsilon}_{\boldsymbol{s}}$ & $<\boldsymbol{d \varepsilon}>$ \\
\hline 1.Cultivos de inundación & $0.985 \pm 0.005$ & $0.971 \pm 0.005(\mathrm{~d})$ & 0 \\
& & $0.990 \pm 0.005(\mathrm{w})$ & 0 \\
\hline $\begin{array}{llll}\text { 2. Vegetación de zonas } \\
\text { de inundables }\end{array}$ & $0.981 \pm 0.012$ & $0.971 \pm 0.005(\mathrm{~d})$ & $0.014 \pm 0.004$ \\
\hline 3.Cultivos y pastizales & $0.985 \pm 0.005$ & $0.971 \pm 0.005$ & 0 \\
\hline 4. Matorrales & $0.981 \pm 0.012$ & $0.971 \pm 0.005$ & $0.014 \pm 0.004$ \\
\hline 5. Bosques de coníferas & $0.989 \pm 0.005$ & $0.971 \pm 0.005$ & $0.019 \pm 0.006$ \\
\hline 6. Bosques de frondosas & $0.973 \pm 0.005$ & $0.971 \pm 0.005$ & $0.019 \pm 0.005$ \\
o mixtos & & & \\
\hline 7. Zonas urbanas & $0.974 \pm 0.014$ & & \\
\hline 8. Suelos desnudos & $0.930 \pm 0.005$ & & \\
\hline 9. Masas de agua & $0.990 \pm 0.005$ & & \\
\hline
\end{tabular}

Tabla 5. Valores umbrales del índice de vegetación observados en cada adquisición (dd/mm/aaaa). NDVI: índice de vegetación de diferencia normalizada; $s$ : píxel de suelo desnudo; $v$ : píxel con cobertura vegetal completa.

\begin{tabular}{lll}
\hline Día & $\mathrm{NDVI}_{\mathrm{s}}$ & $\mathrm{NDVI}_{\mathrm{v}}$ \\
\hline $27 / 03 / 2009$ & 0.198 & 0.656 \\
\hline $30 / 05 / 2009$ & 0.188 & 0.650 \\
\hline $03 / 09 / 2009$ & 0.168 & 0.657 \\
\hline $14 / 03 / 2010$ & 0.156 & 0.640 \\
\hline $21 / 08 / 2010$ & 0.142 & 0.704 \\
\hline $01 / 03 / 2011$ & 0.130 & 0.659 \\
\hline $02 / 04 / 2011$ & 0.088 & 0.455 \\
\hline $04 / 05 / 2011$ & 0.167 & 0.675 \\
\hline
\end{tabular}

De acuerdo con los valores típicos considerados en otros estudios (Anton y Ross, 1990; Olioso, 1995; François et al., 1997), consideramos un valor de 2.5 para el factor $k$ necesario en el 
Mira, M., Gordillo, J., González-Guerrero, O., y Pons, X. (2017): “Análisis comparativo de métodos para la estimación de la emisividad en la banda térmica del sensor TM de Landsat-5”, GeoFocus (Artículos), no 19, p. 55-80. ISSN: 15785157 http://dx.doi.org/10.21138/GF.512

método Wittich1997. Dicho valor aporta una dependencia no lineal a la relación entre la emisividad y el NDVI, variable según la clase de cubierta del suelo y que se satura a partir de cierto valor de NDVI según la cubierta.

\subsection{Cartografía de la emisividad según tres algoritmos}

En la figura 2 se muestra como ejemplo la cartografía de emisividades obtenida según Valor1996. Por analogía, se cartografió así mismo el índice de fracción de cubierta vegetal (figura 3). Con el análisis de ambas imágenes comprobamos que existe un comportamiento similar entre la emisividad y la fracción de la cubierta vegetal, lo que sugiere una correlación entre ambas variables, como era de esperar. Se observa una ligera variación de los parámetros a lo largo de los meses del año, siendo mayor durante los meses de marzo y abril, y disminuyendo en agosto y septiembre coincidiendo con los meses de final de verano. Las superficies donde la cobertura es mayor (mayor valor de $f$ y $\varepsilon$ ) corresponden a superficies forestales localizadas en zonas de montaña, mientras que la presencia de valores inferiores de $f$ y $\varepsilon$ se encuentra en campos destinados a cultivos agrícolas. En contraposición, destaca el comportamiento opuesto en la zona estricta del Delta del Ebro: es en los meses de verano cuando los valores de $f$ y $\varepsilon$ son más elevados debido al crecimiento del arroz, mientras que son menores en los meses de primavera cuando los campos se encuentran secos, en el momento del sembrado del cereal.

\subsection{Evaluación con medidas terreno}

De forma orientativa y a modo de evaluación, se llevó a cabo un ejercicio de comparación entre las estimaciones de emisividad obtenidas por las tres metodologías con datos de satélite y las medidas in situ de emisividad especificadas en la Sección 2.4. Concretamente se tuvieron en cuenta los píxeles clasificados como cultivos de inundación (clase 1), localizados en su mayoría en el Delta, durante los días en que se consideraron con una cubierta de suelo desnudo: las dos adquisiciones de marzo se supusieron correspondientes a suelo desnudo y seco, y las de mayo a suelo desnudo y húmedo. Los valores medios de emisividad observados en las imágenes según los tres algoritmos se resumen en la tabla 6.

Tabla 6. Valores medios de emisividad de la banda térmica de Landsat-5 y su desviación estándar, obtenidos sobre los píxeles clasificados como cultivos de inundación, siguiendo diferentes algoritmos.

\begin{tabular}{|c|c|c|c|c|}
\hline \multirow{2}{*}{$\begin{array}{l}\text { Tipo de } \\
\text { superficie }\end{array}$} & \multirow{2}{*}{$\begin{array}{l}\text { Día } \\
\text { (dd/mm/aaaa) }\end{array}$} & \multicolumn{3}{|c|}{ Emisividad en la banda 6 de Landsat-5 $\left(\varepsilon_{10.4-12.5 \mu \mathrm{m}}\right)$} \\
\hline & & Valor1996 & Sobrino2000 & Wittich1997 \\
\hline \multirow[t]{2}{*}{ Suelo seco } & $27 / 03 / 2009$ & $0.972 \pm 0.003$ & $0.976 \pm 0.006$ & $0.975 \pm 0.003$ \\
\hline & $01 / 03 / 2011$ & $0.972 \pm 0.002$ & $0.973 \pm 0.006$ & $0.973 \pm 0.003$ \\
\hline \multirow[t]{2}{*}{ Suelo húmedo } & $30 / 05 / 2009$ & $0.989 \pm 0.001$ & $0.981 \pm 0.006$ & $0.988 \pm 0.001$ \\
\hline & 04/05/2011 & $0.990 \pm 0.001$ & $0.982 \pm 0.007$ & $0.989 \pm 0.001$ \\
\hline
\end{tabular}


Mira, M., Gordillo, J., González-Guerrero, O., y Pons, X. (2017): “Análisis comparativo de métodos para la estimación de la emisividad en la banda térmica del sensor TM de Landsat-5”, GeoFocus (Artículos), no 19, p. 55-80. ISSN: 15785157 http://dx.doi.org/10.21138/GF.512

En líneas generales observamos que, si se considera la desviación estándar, las estimaciones de los tres métodos se engloban unas a otras. Por lo tanto podemos afirmar que, considerando su desviación estándar, los tres métodos coinciden en las estimaciones de la emisividad del suelo desnudo. Así mismo, sabemos que la emisividad de los suelos en el infrarrojo térmico aumenta de manera significativa con su contenido de agua (Mira et al., 2007, 2010). Como se observa en la $\underline{\text { tabla } 6}$, las estimaciones de emisividad con medidas de satélite lo corroboran, independientemente del algoritmo considerado. Observamos un aumento de la emisividad con el contenido de agua de hasta 0.018, 0.009, 0.016 en los algoritmos de Valor1996, Sobrino2000 y Wittich1997, respectivamente

En relación a su comparación con medidas terreno y considerando un error de medida de \pm 0.005 , tanto las estimaciones de suelo seco como las de suelo húmedo se enmarcan dentro de los valores esperados: $0.963-0.973$ para suelos secos y 0.975 - 0.986 para suelos húmedos. Así mismo, nuestras estimaciones están también de acuerdo con las medidas presentadas por Mira et al. (2007) correspondientes a un suelo de los arrozales de la Albufera de Valencia con distintos contenidos de humedad. 


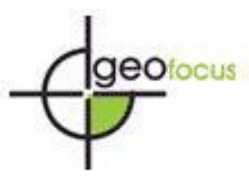

Mira, M., Gordillo, J., González-Guerrero, O., y Pons, X. (2017): “Análisis comparativo de métodos para la estimación de la emisividad en la banda térmica del sensor TM de Landsat-5”, GeoFocus (Artículos), no 19, p. 55-80. ISSN: 15785157 http://dx.doi.org/10.21138/GF.512

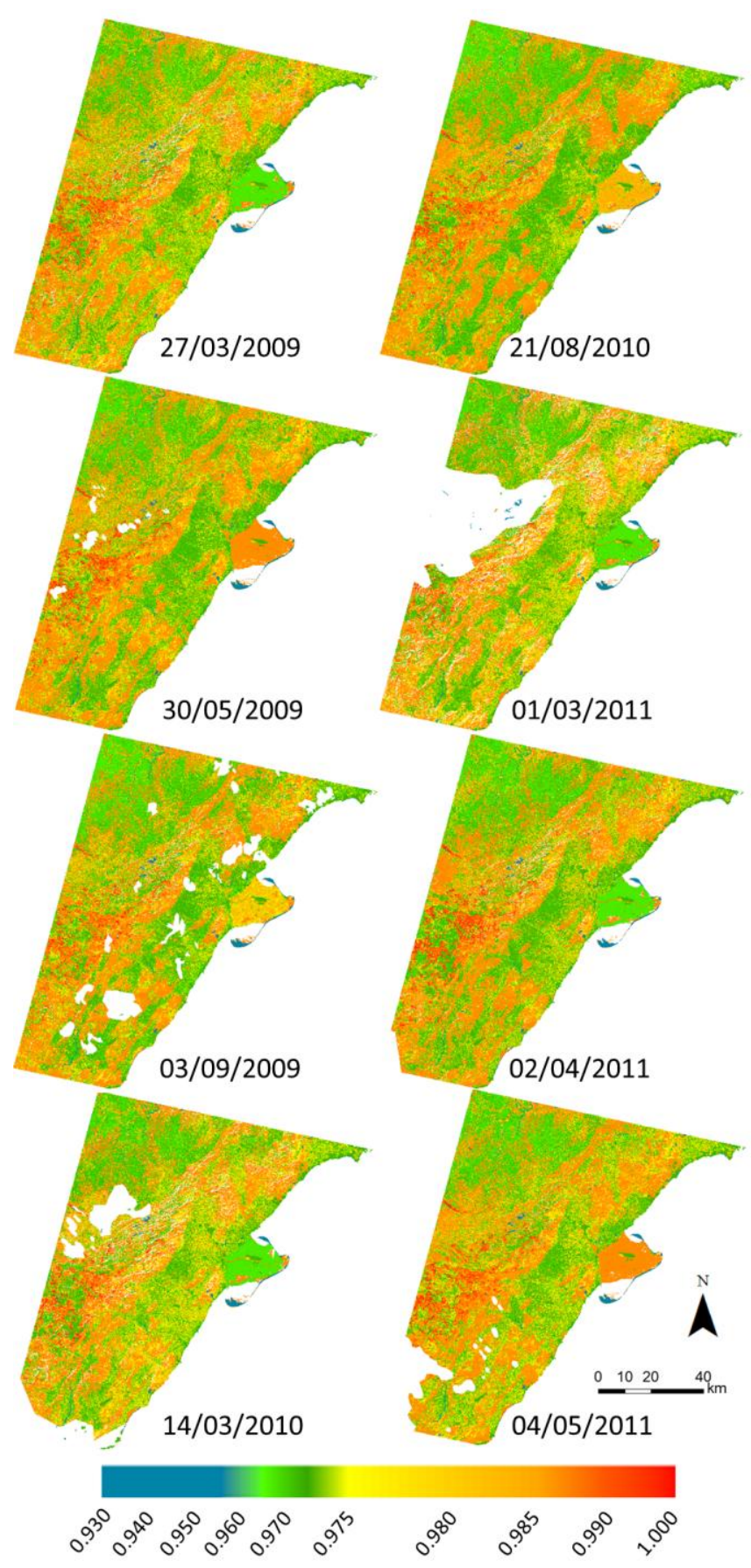

Figura 2. Mapas con los valores de la emisividad térmica de Landsat-5 calculados según la metodología descrita por Valor y Caselles (1996) sobre la zona de estudio en cada una de las adquisiciones ( $\mathrm{dd} / \mathrm{mm} / \mathbf{a a a})$. Los píxeles en blanco corresponden a píxeles clasificados como agua o nubes. 
Mira, M., Gordillo, J., González-Guerrero, O., y Pons, X. (2017): “Análisis comparativo de métodos para la estimación de la emisividad en la banda térmica del sensor TM de Landsat-5”, GeoFocus (Artículos), no 19, p. 55-80. ISSN: 1578$5157 \mathrm{http}: / / \mathrm{dx}$.doi.org/10.21138/GF.512

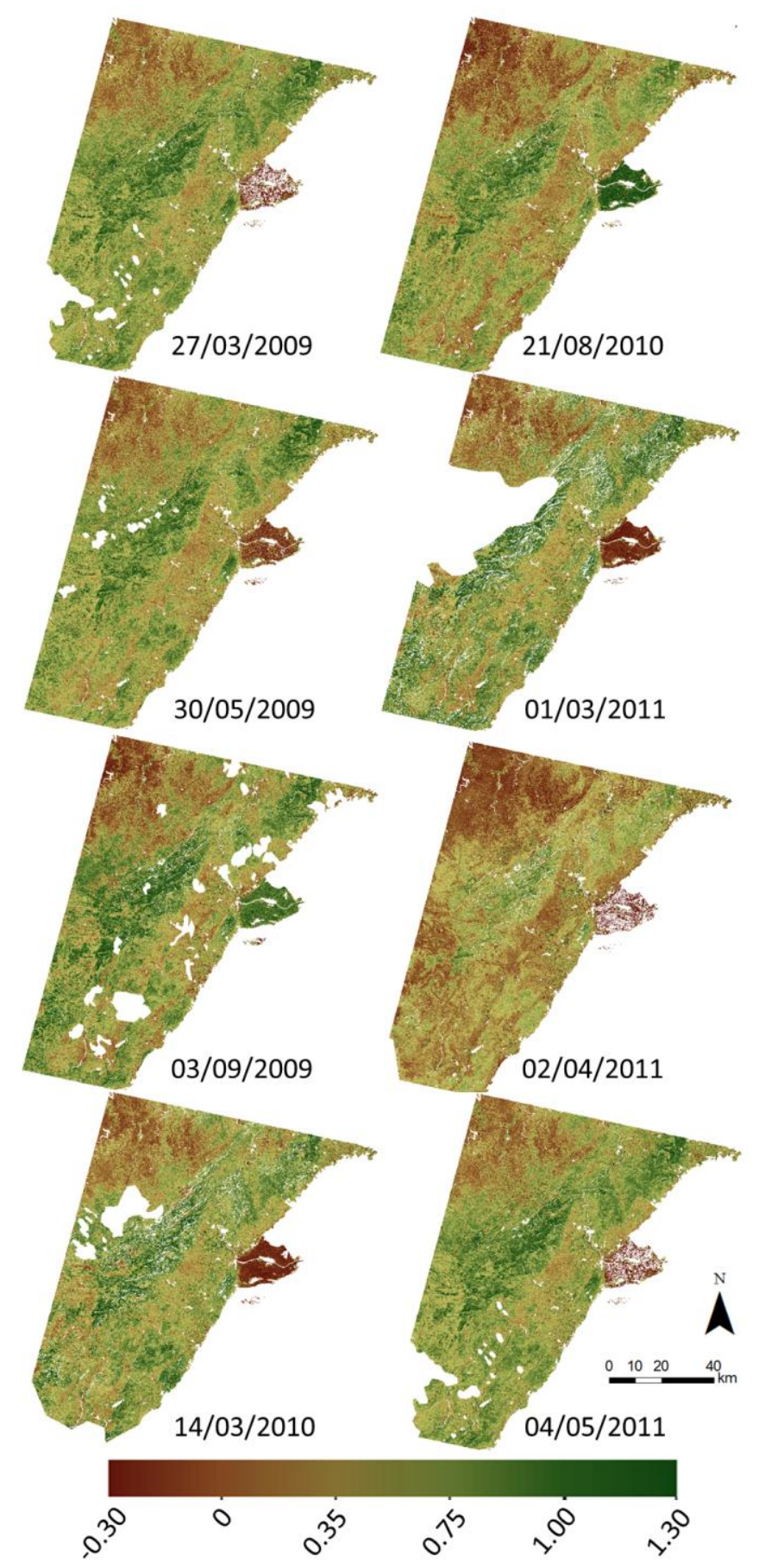

Figura 3. Mapas con los valores del índice de la fracción de cubierta vegetal $(f)$ observado en cada adquisición Landsat-5 (dd/mm/aaa) sobre la zona de estudio. Los píxeles en blanco corresponden a zonas clasificadas como agua o nubes. 
Mira, M., Gordillo, J., González-Guerrero, O., y Pons, X. (2017): “Análisis comparativo de métodos para la estimación de la emisividad en la banda térmica del sensor TM de Landsat-5”, GeoFocus (Artículos), no 19, p. 55-80. ISSN: 15785157 http://dx.doi.org/10.21138/GF.512

\subsection{Evolución temporal por clases temáticas y comparación entre métodos}

Tras considerar por separado las clases temáticas, se representa en la figura 4 la variación temporal de los valores medios de la emisividad, del índice de fracción de cubierta vegetal y del NDVI, según los tres métodos. En líneas generales, destaca la similar evolución temporal entre las estimaciones de emisividad y los índices NDVI y $f$, como era de esperar. Esto se debe a que un aumento del NDVI o de $f$ implica mayor cobertura vegetal y, generalmente, un aumento de la emisividad. Existe en consecuencia una correlación directa entre estas variables, de ahí su dependencia en los algoritmos. En cuanto a las diferencias de emisividad observadas entre métodos, si bien siguen la misma dinámica temporal, los valores absolutos difieren entre sí. Esto se debe a los algoritmos en sí y a los valores extremos establecidos por las diferentes constantes implicadas (i.e., $\left.\mathrm{NDVI}_{\mathrm{s}}, \mathrm{NDVI}_{v}, \varepsilon_{s}, \varepsilon_{v}, \ldots\right)$. A continuación realizamos un análisis detallado por clase temática.

- Clase 1 o cultivos de inundación. Representada en su mayor parte por los arrozales del Delta, presenta valores de emisividad inferiores en los meses de marzo y abril, cuando los campos se encuentran secos en el periodo previo al sembrado. Los valores aumentan en mayo, al igual que sucede con el índice de fracción de cubierta vegetal, debido a la presencia de humedad y a pequeñas masas de agua durante el periodo de sembrado del arroz. Los niveles más altos se observan en los meses de agosto y septiembre, cuando las plantaciones se encuentran en su momento óptimo y tanto el NDVI como la cubierta vegetal alcanzan los valores álgidos.

- Clase 2 o vegetación de zonas inundables. Corresponde a las salinas y marismas, una cubierta con poca presencia en las imágenes. Por tratarse de zonas húmedas, su emisividad prácticamente no varía a lo largo del tiempo, independientemente del método, presentando valores siempre por encima de 0.98 .

- Clase 3 o cultivos y pastizales. Esta clase presenta valores muy constantes de las tres variables a lo largo de todo el periodo. No obstante, se aprecia una suave evolución a lo largo del año, con valores que se van incrementando durante los meses de primavera, alcanzando la mayor emisividad en mayo. Una vez entrados los meses de verano, la emisividad disminuye. Las emisividades estimadas con el método Valor1996 son más próximas a los valores obtenidos con el método Wittich1997 que a las obtenidas con el método Sobrino2000.

- Clase 4 o matorrales. Esta clase presenta valores de emisividad muy constantes, a excepción de una disminución de su valor en abril del 2011 por un cambio en la fracción de cubierta vegetal, como indican los valores de $f$ y NDVI. Las emisividades de Wittich1997 difieren en valor absoluto respecto a las de Sobrino2000 y Valor1996, muy probablemente debido a las diferencias en el valor del $\mathrm{NDVI}_{\mathrm{v}}$ considerado. 


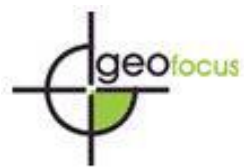

Revista Internacional de Ciencia y Tecnologia de la Información Geográfica International Review of Geographical Information Science and Technology

Mira, M., Gordillo, J., González-Guerrero, O., y Pons, X. (2017): “Análisis comparativo de métodos para la estimación de la emisividad en la banda térmica del sensor TM de Landsat-5”, GeoFocus (Artículos), n 19, p. 55-80. ISSN: 15785157 http://dx.doi.org/10.21138/GF.512
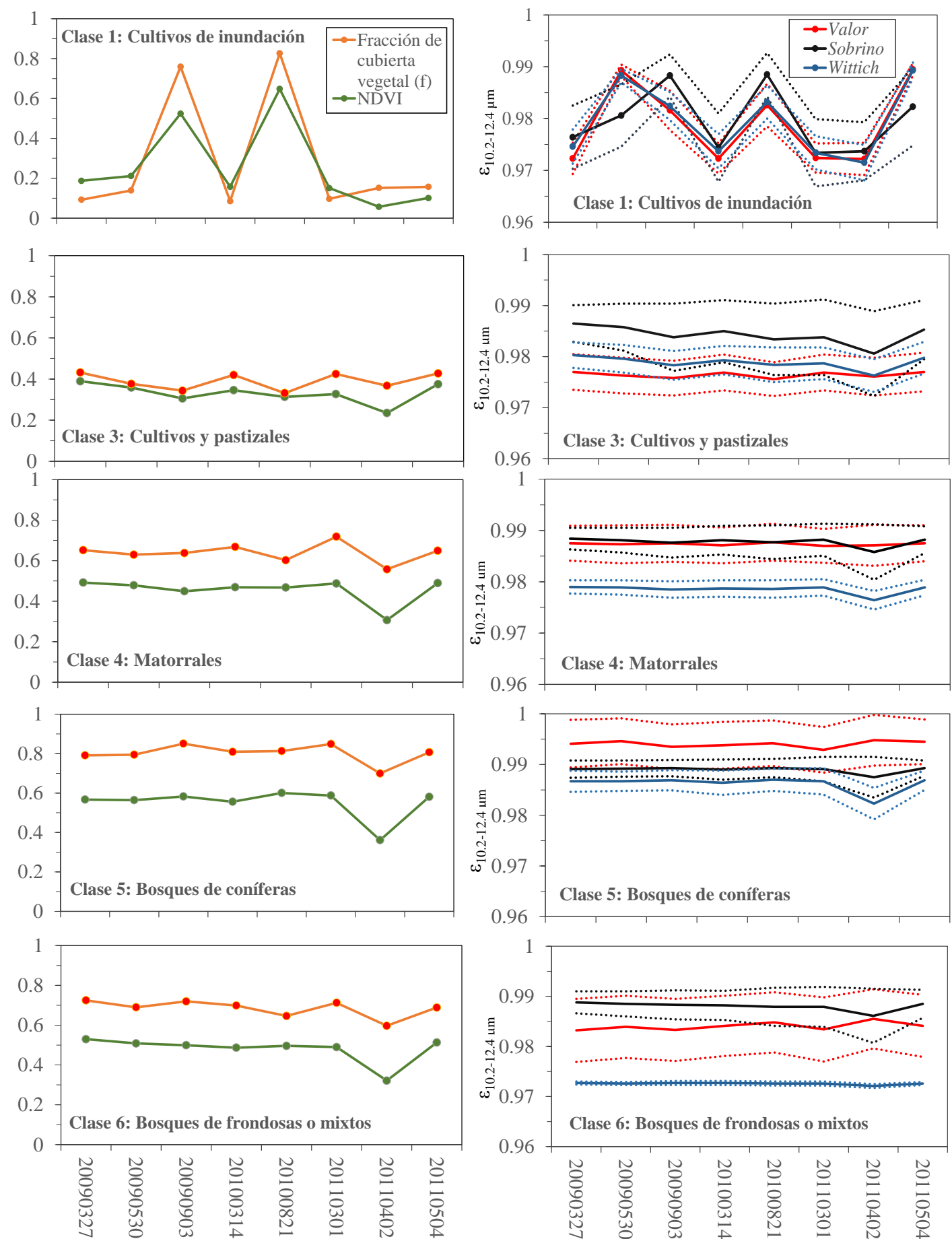

Figura 4. Evolución temporal del NDVI y el índice de fracción de cubierta vegetal, $f$ (izquierda) y la emisividad $\varepsilon$ en la banda térmica de Landsat-5 (derecha) según diferentes cubiertas definidas en la tabla 1 . En líneas de puntos se representa la desviación estándar de la emisividad. 
Mira, M., Gordillo, J., González-Guerrero, O., y Pons, X. (2017): “Análisis comparativo de métodos para la estimación de la emisividad en la banda térmica del sensor TM de Landsat-5”, GeoFocus (Artículos), no 19, p. 55-80. ISSN: 1578$5157 \mathrm{http}: / / \mathrm{dx}$.doi.org/10.21138/GF.512

- Clase 5 o bosques de coníferas. Precisamente por tratarse de una superficie que no varía de forma importante con el tiempo, presenta una evolución casi nula de la emisividad. Excepcionalmente, se observa una disminución de la emisividad (en 0.01) en abril del 2011 debido a una disminución de la cobertura vegetal, probablemente a una poda o tala de los árboles, como indican los valores de NDVI y $f$.

- Clase 6 o bosques de frondosas o mixtos. Contrariamente a lo que era de esperar, esta cubierta tampoco presenta una gran variabilidad, presentando la misma tendencia que la clase anterior en abril de 2011.

- Clase 7 o zonas urbanas, clase 8 o suelos desnudos, y clase 9 o masas de agua. La emisividad de estas clases no depende del índice de vegetación y se les asignó un valor constante, indicado en la tabla 4.

\subsection{Análisis de las estimaciones de emisividad relativas al método Wittich1997}

Para tener una mejor perspectiva de las diferencias existentes entre las metodologías se analizaron los estadísticos tras considerar como referencia el algoritmo de Wittich1997. Se escogió una pequeña área que incluye la zona del Delta del Ebro y sus alrededores (ver figura 5), encontrándose caracterizada por la presencia tanto de zonas planas como montañosas.

Con el análisis de los valores de la tabla 7 observamos que, si consideramos la desviación estándar, las diferencias entre las estimaciones de emisividad de Valor1996 y Wittich1997 difieren hasta 0.011 unidades, y los de Sobrino2000 y Wittich1997 hasta 0.014. Por lo tanto, deducimos que las diferencias existentes entre métodos superan el error asociado a la medida de la emisividad sobre el terreno, que es de 0.005 (Mira et al., 2007). Además, observamos que las diferencias con el método Wittich1997 son generalmente mayores para el método Sobrino2000 (alrededor de $0.007 \pm 0.006$ ) que para el de Valor 1996 (alrededor de 0.003 \pm 0.006 ).

Las mayores disparidades se localizan en las superficies correspondientes a las zonas de montaña $(0.015<\Delta \varepsilon<0.02)$. En estas zonas la existencia de pendiente provoca valores inadecuados de reflectancias, afectando al cálculo del NDVI y del índice de fracción vegetal. Las cubiertas clasificadas como masas de agua, zonas urbanas y suelos desnudos (clases 7 a 9) no muestran diferencias entre métodos ya que se utilizaron valores constantes e iguales en las tres metodologías.

Con el análisis de los resultados de la tabla 8, correspondientes a dos días concretos, observamos que en general el método Valor1996 respecto a Sobrino2000 presenta estimaciones de emisividad más cercanas a las de Wittich1997, a excepción de la clase 5. Además, observamos que los valores son del mismo orden para una misma clase, independientemente del día de la imagen. 


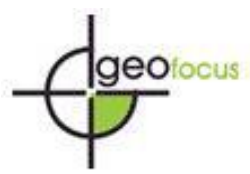

Revista Internacional de Ciencia y Tecnologia de la Información Geográfica

International Review of Geographical Information Science and Technology

Mira, M., Gordillo, J., González-Guerrero, O., y Pons, X. (2017): “Análisis comparativo de métodos para la estimación de la emisividad en la banda térmica del sensor TM de Landsat-5”, GeoFocus (Artículos), no 19, p. 55-80. ISSN: 15785157 http://dx.doi.org/10.21138/GF.512
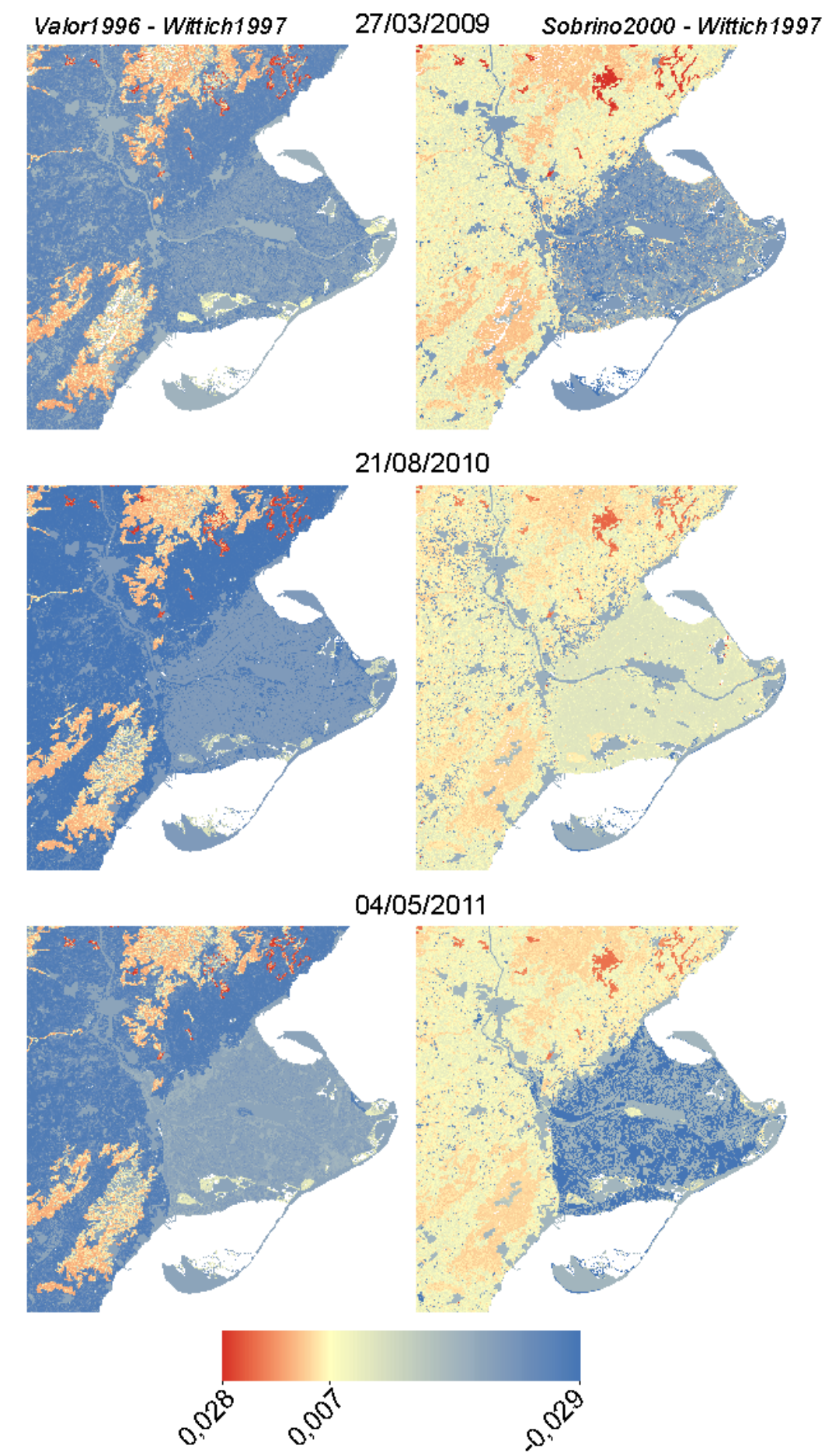

Figura 5. Diferencias de emisividad entre las estimaciones de Valor1996 y Wittich1997 (izquierda) y Sobrino2000 y Wittich1997 (derecha), correspondientes a imágenes de marzo, agosto y mayo. 
Mira, M., Gordillo, J., González-Guerrero, O., y Pons, X. (2017): “Análisis comparativo de métodos para la estimación de la emisividad en la banda térmica del sensor TM de Landsat-5”, GeoFocus (Artículos), nº 19, p. 55-80. ISSN: 15785157 http://dx.doi.org/10.21138/GF.512

Teniendo en cuenta el error de medida de la emisividad (0.005 según Mira et al., 2007), podemos considerar que no existe una desviación o Bias significativo entre métodos, y que el RMSE es significativo tan solo para ciertas cubiertas del suelo: clase 4 y 6 para Valor1996, y todas las clases excepto la clase 5 para Sobrino2000. Destaca el elevado valor observado en la clase 1 (cultivos de inundación) según Sobrino2000, con valores de hasta 0.011. Esto se explica por la diferencia entre los valores de $\mathrm{NDVI}_{\mathrm{s}}$ considerada por ambos métodos, que es menor en el caso de Wittich1997 respecto al de Sobrino2000 (0.08 respecto a $\sim 0.17)$.

Tabla 7. Valor medio de las diferencias absolutas de emisividad y su desviación estándar, entre los algoritmos de Valor1996 y Sobrino2000 respecto al de Wittich1997. El ámbito de estudio se limita al de la figura 5.

\begin{tabular}{ccc}
\hline \multirow{2}{*}{$\begin{array}{c}\text { Día } \\
(\mathrm{dd} / \mathrm{mm} / \text { aaaa })\end{array}$} & $\begin{array}{c}\text { Diferencias absolutas de emisividad entre métodos } \\
\text { y su desviación estándar }\end{array}$ \\
\cline { 2 - 3 } & $\left|\varepsilon_{\text {Valor 1996- }} \varepsilon_{\text {Wittich1997 }}\right|$ & $\left|\varepsilon_{\text {Sobrino2000 }} \varepsilon_{\text {Wittich1997 }}\right|$ \\
\hline $27 / 03 / 2009$ & $0.003 \pm 0.007$ & $0.008 \pm 0.004$ \\
\hline $30 / 05 / 2009$ & $0.003 \pm 0.007$ & $0.008 \pm 0.006$ \\
\hline $03 / 09 / 2009$ & $0.003 \pm 0.006$ & $0.008 \pm 0.006$ \\
\hline $14 / 03 / 2010$ & $0.003 \pm 0.006$ & $0.008 \pm 0.006$ \\
\hline $21 / 08 / 2010$ & $0.003 \pm 0.007$ & $0.007 \pm 0.005$ \\
\hline $01 / 03 / 2011$ & $0.002 \pm 0.005$ & $0.007 \pm 0.006$ \\
\hline $02 / 04 / 2011$ & $0.005 \pm 0.006$ & $0.007 \pm 0.007$ \\
\hline $04 / 05 / 2011$ & $0.003 \pm 0.006$ & $0.007 \pm 0.005$ \\
\hline
\end{tabular}

Tabla 8. Estadísticos asociados a la comparación de métodos de emisividad, tomando como referencia el método Wittich1997. Valores obtenidos sobre cada clase temática en dos días. $R M S E_{a}$ y $R M S E_{r}$ : error cuadrático medio absoluto y relativo, respectivamente; Bias: desviación.

\begin{tabular}{l|ccc|ccc}
\hline 03/09/2009 & \multicolumn{3}{|c|}{ Valor1996 respecto Wittich1997 } & \multicolumn{3}{c}{ Sobrino2000 respecto Wittich1997 } \\
\cline { 2 - 7 } 04/05/2011 & $R M S E_{a}$ & $R M S E_{r}(\%)$ & Bias & RMSE & RMSE $(\%)$ & Bias \\
\hline Clase 1 & 0.0009 & 0.09 & -0.0008 & 0.006 & 0.6 & -0.0007 \\
& 0.0006 & 0.06 & -0.0008 & 0.011 & 1.1 & -0.007 \\
\hline Clase 2 & 0.004 & 0.4 & -0.0017 & 0.007 & 0.7 & -0.0016 \\
& 0.006 & 0.6 & -0.0016 & 0.004 & 0.4 & 0.002 \\
\hline Clase 3 & 0.003 & 0.3 & -0.0002 & 0.007 & 0.7 & -0.0002 \\
& 0.003 & 0.3 & -0.008 & 0.007 & 0.7 & 0.006 \\
\hline Clase 4 & 0.010 & 1.0 & -0.0002 & 0.009 & 1.0 & -0.0002 \\
& 0.009 & 0.9 & -0.0002 & 0.010 & 1.0 & 0.009 \\
\hline Clase 5 & 0.005 & 0.5 & -0.004 & 0.002 & 0.2 & -0.004 \\
& 0.005 & 0.5 & -0.003 & 0.0019 & 0.19 & 0.0018 \\
\hline Clase 6 & 0.015 & 1.5 & -0.00018 & 0.015 & 1.6 & -0.00018 \\
& 0.013 & 1.4 & -0.00017 & 0.016 & 1.7 & 0.016 \\
\hline
\end{tabular}


Mira, M., Gordillo, J., González-Guerrero, O., y Pons, X. (2017): “Análisis comparativo de métodos para la estimación de la emisividad en la banda térmica del sensor TM de Landsat-5”, GeoFocus (Artículos), no 19, p. 55-80. ISSN: 15785157 http://dx.doi.org/10.21138/GF.512

\section{Discusión}

La evaluación de las estimaciones de emisividad obtenidas con datos Landsat-5 TM con medidas terreno sobre diferentes suelos secos y húmedos proporciona una primera aproximación de su bondad para este tipo de cubiertas, puesto que se incluyen dentro del intervalo de valores esperable. Para validar correctamente las estimaciones de satélite se deberían comparar con medidas de emisividad realizadas sobre la zona de estudio simultáneamente al paso del satélite sobre las diferentes cubiertas. Es por eso que el objetivo planteado en este trabajo, lejos de ser una validación de métodos, es la simple comparación de las estimaciones proporcionadas por diferentes métodos.

Las diferencias de emisividad observadas entre los métodos Valor1996, Sobrino2000 y Wittich1997 dependen del tipo de cubierta considerado y son mayores en zonas montañosas debido al efecto de la pendiente en la radiación recibida por el sensor. En superficies forestales, localizadas en alturas elevadas y donde las pendientes son mayores, los algoritmos Valor1996 y Sobrino2000 muestran valores más próximos entre sí. Esto se debe probablemente por la dependencia común con el índice de fracción de cubierta vegetal y el factor de cavidad, importante en este tipo de cubiertas. En superficies planas correspondientes a cultivos de arroz, cultivos en general y pastizales las emisividades son reproducidas de forma similar por el método Valor1996 y Wittich1997.

Tomando como referencia arbitrariamente uno de los métodos es posible analizar las diferencias relativas entre sí. Las métricas calculadas no corresponden a errores absolutos de estimación de la emisividad, sino a la incertidumbre adicional por el hecho de considerar uno u otro método para su estimación. Tomando como referencia el método Wittich1997 se observa una mayor similitud con las estimaciones del método Valor1996, con valores medios del RMSE $\mathrm{r}_{\mathrm{r}}$ de $0.6 \%$, variando desde $0.06 \%$ para los cultivos de inundación a $1.5 \%$ para los bosques de frondosas o mixtos. Las diferencias observadas respecto al método Sobrino2000 son ligeramente mayores, con valores medios del RMSE $\mathrm{r}_{\mathrm{r}}$ de $0.8 \%$, variando desde $0.19 \%$ para los bosques de coníferas a $1.7 \%$ para los bosques de frondosas o mixtos.

\section{Conclusión}

En conclusión, la evaluación de las estimaciones de satélite con medidas terreno demuestra que proporcionan estimaciones enmarcadas dentro de los valores esperados. La comparación de métodos aquí realizada destaca la importancia en la elección del algoritmo a aplicar y en la correcta definición de las constantes de entrada teniendo en cuenta las características espectrales de la zona de estudio.

Para un análisis más completo y exhaustivo, consideramos que este trabajo se podría mejorar con la consideración de una larga serie temporal de imágenes Landsat, un análisis más detallado según los tipos de cubierta, y el estudio de otros algoritmos de emisividad. De forma complementaria, el cálculo de la temperatura de la superficie terrestre con los productos de emisividad obtenidos con cada método permitiría realizar una mejor estimación de la incertidumbre asociada. 
Mira, M., Gordillo, J., González-Guerrero, O., y Pons, X. (2017): “Análisis comparativo de métodos para la estimación de la emisividad en la banda térmica del sensor TM de Landsat-5”, GeoFocus (Artículos), no 19, p. 55-80. ISSN: 15785157 http://dx.doi.org/10.21138/GF.512

\section{Agradecimientos}

Este estudio fue financiado por el Ministerio Español de Ciencia e Innovación (contrato de investigación "Juan de la Cierva" de la Dra. Mira), la Generalitat de Catalunya (GRUMETS SGR2014-1491) y la "Institució Catalana de Recerca i Estudis Avançats" ("ICREA Academia Excellence in Research" del Dr. Pons). Asimismo, la investigación se enmarca en los proyectos ACAPI (CGL2015-69888-P, MINECO/FEDER) y Ecopotential (EC H2020 641762-2).

\section{Referencias bibliográficas}

Anton, Y.A., Ross, Y.K. (1990): "Emissivity of a soil vegetation system", Soviet Journal of Remote Sensing, 7, pp. 859-869.

Baldridge, A. M., Hook, S. J., Grove, C. I., Rivera, G. (2009): “The ASTER spectral library version 2.0", Remote Sensing of Environment, 113, 4, pp. 711-715.

Bossard, M., Feranec, J., Otahel, J. (2000). CORINE land cover technical guide - Addendum 2000. Technical Report No. 40. Copenhagen: European Environmental Agency 105 pp.

Buettner, K. J. K., Kern, C.D. (1965): "The determination of infrared emissivities of terrestrial surfaces," Journal of Geophysical Research, 70, pp. 1329-1337.

Caselles, E., Sobrino, J.A. (1989): "Determination of frost in orange groves from NOAA-9 AVHRR data", Remote Sensing of Environment, 29, pp.135-146.

Caselles, E., Valor, E., Abad, F., Caselles, V. (2012): “Automatic classification-based generation of thermal infrared land surface emissivity maps using AATSR data over Europe", Remote Sensing of Environment, 124, pp.321-333.

Coll, C., Caselles, V., Galve, J.M., Valor, E., Niclòs, R., Sánchez, J., Rivas, R. (2005): “Ground measurements for the validation of land surface temperatures derived from AATSR and MODIS data", Remote Sensing of Environment, 97, pp. 288-300.

Coll, C., Valor, E., Galve, J.M., Mira, M., Bisquert, M., García-Santos, V., Caselles, E., Caselles, V. (2012): "Long-term accuracy assessment of land surface temperatures derived from the Advanced Along-Track Scanning Radiometer", Remote Sensing of Environment, 116, pp. 211-225.

Coll, C., Valor, E., Caselles, V., Niclòs, R. (2003): “Adjusted Normalized Emissivity Method for surface temperature and emissivity retrieval from optical and thermal infrared remote sensing data", Journal of Geophysical Research, 108(D23):4739, doi:10.1029/2003JD003688.

Dana, R.W. (1969): "Measurement of 8-14 micron emissivity of igneous rocks and mineral surfaces", Goddard Space Flight Center, Greenbelt, MD, NASA Sci. Rep. NSG-632.

Dash, P., Göttsche, F.M., Olesen, F.S. (2002): "Potential of MSG for surface temperature and emissivity estimation: considerations for real-time applications", International Journal of Remote Sensing, 23, 20, pp. 4511-4518. 
Mira, M., Gordillo, J., González-Guerrero, O., y Pons, X. (2017): “Análisis comparativo de métodos para la estimación de la emisividad en la banda térmica del sensor TM de Landsat-5”, GeoFocus (Artículos), nº 19, p. 55-80. ISSN: 15785157 http://dx.doi.org/10.21138/GF.512

Dash, P., Göttsche, F.M., Olesen, F.S., Fischer, H. (2005): "Separating surface emissivity and temperature using two-channel spectral indices and emissivity composites and comparison with a vegetation fraction method", Remote Sensing of Environment, pp. 961-17.

François, C., Ottlé, C., Prévot, L. (1997): “Analytical parameterization of canopy directional emissivity and directional radiance in the thermal infrared. Application on the retrieval of soil and foliage temperatures using two directional measurements", International Journal of Remote Sensing, 18, pp. 2587-2621.

Gillespie, A., Rokugawa, S., Matsunaga, T., Cothern, J.S., Hook, S., Kahle, A.B. (1998): “A temperature and emissivity separation algorithm for Advanced Spaceborne Thermal Emission and Reflection Radiometer (ASTER) images", Ieee Transactions on Geoscience and Remote Sensing, 36, pp. 1113-1126.

Jacob, F., Petitcolin, F., Schmugge, T., Vermote, E., Ogawa, K., French, A. (2004): “Comparison of land surface emissivity and radiometric temperature from MODIS and ASTER sensors", Remote Sensing of Environment, 83, pp. 1-18.

Mira, M., Valor, E., Boluda, R., Caselles, V., Coll, C. (2007): "Influence of soil water content on the thermal infrared emissivity of bare soils: Implication for land surface temperature determination", Journal of Geophysical Research, 12, F04003, doi: 10.1029/2007JF000749.

Mira, M., Valor, E., Caselles, V., Rubio, E., Coll, C., Galve, J.M., Niclòs, R., Sánchez, J.M., Boluda, R. (2010): "Soil moisture effect on thermal infrared (8-13 m) emissivity", IEEE Transactions on Geoscience and Remote Sensing, 48, 5, pp. 2251-2260.

Mira, M., Olioso, A., Gallego-Elvira, B., Courault, D., Garrigues, S., Marloie, O., Hagolle, O., Guillevic, P., Boulet, G. (2016); "Uncertainty assessment of surface net radiation derived from Landsat images", Remote Sensing of Environment, 175, pp. 251-270.

Nerry, F., Labed, J., Stoll, M.P. (1990a): "Spectral properties of land surfaces in the thermal infrared band. Part I: Laboratory measurements of absolute spectral emissivity signatures", Journal of Geophysical Research, 95, B5, pp. 7027-7044.

Nerry, F., Labed, J., Stoll, M.P. (1990b): "Spectral properties of land surfaces in the thermal infrared band. Part II: Field method for spectrally averaged emissivity measurements", Journal of Geophysical Research, 95, B5, pp. 7045-7062.

Norman, J.M., Becker, F. (1995): "Terminology in thermal infrared remote-sensing of natural surfaces", Agricultural and Forest Meteorology, 77, pp. 153-166.

Olioso, A. (1995): "Simulating the relationship between thermal emissivity and the normalized difference vegetation index", International Journal of Remote Sensing, 16, 16, pp. 3211-3216.

Olioso, A., Sòria, G., Sobrino, J., Duchemin, B. (2007): "Evidence of low land surface termal infrared emissivity in the presence of dry vegetation", IEEE Geoscience and Remote Sensing Letters, 4, pp. 112-116.

Palà, V., Pons, X. (1995): "Incorporation of relief in polynomial-based geometric corrections", Photogrammetric Engineering and Remote Sensing, 61(7), pp. 935-944. 
Mira, M., Gordillo, J., González-Guerrero, O., y Pons, X. (2017): “Análisis comparativo de métodos para la estimación de la emisividad en la banda térmica del sensor TM de Landsat-5”, GeoFocus (Artículos), no 19, p. 55-80. ISSN: 15785157 http://dx.doi.org/10.21138/GF.512

Payan, V., Royer, A. (2004): "Analysis of the Temperature Emissivity Separation (TES) algorithm applicability and sensitivity", International Journal of Remote Sensing, 25, pp. 15-37.

Peres, L., DaCamara, C. (2004): "Land surface temperature and emissivity estimation based on the two-temperature method: sensitivity analysis using simulated MSG/SEVIRI data", Remote Sensing of Environment, 91, pp. 377-389.

Pons, X., Moré, G., Pesquer, L. (2010): “Automatic matching of Landsat image series to high resolution orthorectified imagery", Proceedings of the ESA Living Planet Symposium, CD-ROM edition. ESA reference document: SP-686. ESA Living Planet Symposium Bergen (Noruega).

Pons, X., Pesquer, L., Cristóbal, J., González-Guerrero, O. (2014): “Automatic and improved radiometric correction of Landsat imagery using reference values from MODIS surface reflectance images", International Journal of Applied Earth Observations and Geoinformation, 33, pp. 243254.

Pons, X., Solé-Sugrañes, L. (1994): “A simple radiometric correction model to improve automatic mapping of vegetation from multispectral satellite data", Remote Sensing of Environment, 48, pp. 191-204.

Rouse, J.W., Haas, R.H., Schell, J.A., Deering, D.W., Harlan, J.C. (1974): "Monitoring the vernal advancement of retrogradation of natural vegetation", NASA/GSFC, Type III, Final Report, Greenbelt, MD, p. 371.

Rubio, E., Caselles, V., Badenas, C. (1997): "Emissivity measurements of several soils and vegetation types in the 8-14 $\mu \mathrm{m}$ wave band: analysis of two field methods", Remote Sensing of Environment, 59, pp. 490-521.

Rubio, E., Caselles, V., Coll, C., Valor, E., Sospedra, F. (2003): "Thermal-infrared emissivities of natural surfaces: improvements on the experimental set-up and new measurements", International Journal of Remote Sensing, 24, 24, 5379-5390.

Salisbury, J.W., D'Aria, D.M. (1992a): "Emissivity of terrestrial materials in the 8-14 $\mu \mathrm{m}$ atmospheric window", Remote Sensing of Environment, 42, 2, pp. 83-106.

Salisbury, J.W., D'Aria, D.M. (1992b): "Infrared (8-14 $\mu \mathrm{m})$ remote sensing of soil particle size", Remote Sensing of Environment, 42, 2, pp. 157-165.

Sobrino, J., El Kharraz, J., Li, Z.L. (2003): "Surface temperature and water vapor retrieval from MODIS data", International Journal of Remote Sensing, 24(24):5161-5182.

Sobrino, J., Jiménez-Muñoz, J., El-Kharraz, J., Gómez, M., Romaguera, M., Sòria, G. (2004a): "Single-channel and two-channel methods for land surface temperature retrieval from DAIS data and its application to the Barrax site", International Journal of Remote Sensing, 25, 1, pp. 215-230.

Sobrino, J., Jiménez-Muñoz, J., Paolini, L. (2004b): "Land surface temperature retrieval from Landsat TM 5", Remote Sensing of Environment, 90, pp. 434-440.

Sobrino, J.A., Raissouni, N. (2000); “Toward remote sensing methods for land cover dynamic monitoring: application to Morocco", International Journal of Remote Sensing, 21, pp. 353-366. 
Mira, M., Gordillo, J., González-Guerrero, O., y Pons, X. (2017): “Análisis comparativo de métodos para la estimación de la emisividad en la banda térmica del sensor TM de Landsat-5”, GeoFocus (Artículos), n 19, p. 55-80. ISSN: 15785157 http://dx.doi.org/10.21138/GF.512

Sobrino, J., Sòria, G., Prata, A.J. (2004c): "Surface temperature retrieval from Along Track Scanning Radiometer 2 data: Algorithms and validation", Journal of Geophysical Research, 109D11101, doi:10.1029/2003JD004212.

Sòria, G., Sobrino, J. (2006): "Envisat/AATSR derived land surface temperature over a heterogeneous region", Remote Sensing of Environment, 111(4), 409-422.

Valor, E., Caselles, V. (1996): "Mapping land surface emissivity from NDVI: Application to European, African, and South American areas", Remote Sensing of Environment, 57, pp. 167-184.

Van de Griend, A.A., Owe, M. (1993): "On the relationship between thermal emissivity and the normalized difference vegetation index surfaces", International Journal of Remote Sensing, 14, 6, pp. 1119-1131.

Wan, Z.M., Dozier, J. (1989): "Land-surface temperature measurement from space: physical principles and inverse modeling", IEEE Transactions on Geoscience and Remote Sensing, 27, 268278, doi: $10.1109 / 36.1 \mathrm{~g} 7668$.

Wan, Z., Zhang, Y., Zhang, Q., Li, Z.L. (2002): "Validation of the land surface temperature products retrieved from Terra Moderate Resolution Imaging Spectroradiometer data", Remote Sensing of Environment, 83, pp. 163-180.

Wan, Z., Zhang, Y., Zhang, Q., Li, Z.L. (2004): "Quality assessment and validation of the MODIS global land surface temperature”, International Journal of Remote Sensing, 25, pp. 261-274.

Wittich, K.P. (1997): "Some simple relationship between land-surface emissivity, greenness and the plant cover fraction for use in satellite remote sensing", International Journal of Biometeorology, 41, pp. 58-64.

WWW1. GlobCover Portal. http://due.esrin.esa.int/page_globcover.php

WWW2. Geoportal SIOSE. http://www.siose.es/

WWW3. CORINE Land Cover. https://www.ign.es/ign/layoutIn/corineLandCover.do

WWW4. ASTER Spectral Library. http://speclib.jpl.nasa.gov/ 